\title{
Assess the Knowledge and Expressed Practices regarding PPTCT (Prevention of Parent to Child Transmission of HIV) among Nursing Personnel in selected Health Care Centers Ambala, District Haryana
}

\author{
Rama Thakur(M.Sc. $)^{1}$, Manjari Rana (MSc) ${ }^{2}$, Adiba Siddiqui ( MSc) ${ }^{3}$ \\ ${ }^{1}$ Student M.Sc. Nursing, Department of Obstetrics and Gynaecology Nursing, Maharishi Markandeshwar University, Haryana, India \\ ${ }^{2}$ Associate Professor Department of Community Health Nursing, Maharishi Markandeshwar University, Haryana, India \\ ${ }^{3}$ Associate Professor, Department of Obstetrics and Gynaecology Nursing, Maharishi Markandeshwar University, Haryana, India
}

M. M. COLLEGE OF NURSING, M. M. UNIVERSITY, MULLANA, AMBALA

\begin{abstract}
Background: Nursing personnel are facing the greatest challenge of handling the HIV transmission from mother to child because of their vulnerability. The present study was aimed to assess the knowledge and expressed practices regarding PPTCT (prevention of parent to child transmission of HIV) among nursing personnel in selected health care centers Ambala, District Haryana. Materials and Methods: A descriptive study was carried out among a total sample of 100 nursing personnel in selected health care centers. Data was collected by using structured knowledge questionnaire and expressed practices checklist. Descriptive and inferential statistics were utilized for data analysis. Results: The main finding of the study revealed that association of knowledge score of nursing personnel were found significant with those who had attended classes for GFATM. Whereas association of expressed practices score of nursing personnel were found significant with education, work experience and in those who had classes for GFATM. There is mild positive correlation between knowledge and expressed practices of nursing personnel but was non significant. Interpretation and conclusion: Study concluded that nursing personnel had below average knowledge and poor practices regarding prevention of parent to child transmission of $\mathrm{HIV}$.
\end{abstract}

Keywords: Knowledge, Expressed practices, PPTCT, Nursing personnel

\section{Introduction}

Parent to child transmission of HIV can occur from an HIV infected mother to her child during pregnancy, labor and delivery, or breastfeeding through breast milk. Parent -tochild transmission of HIV is also called perinatal transmission of HIV. It is the most common way that children become infected with HIV. ${ }^{1}$ HIV is transmitted through sexual contact with an infected individual, through mother-to-child transmission, through sharing of sharp instruments with an infected person and transfusion of infected blood and blood-products. Mother to child transmission, which occurs when a mother passes on the virus to her child during pregnancy, labor and breastfeeding, is responsible for an estimated $20 \%$ of all HIV infections and more than $95 \%$ of pediatric HIV transmissions .

According to $\mathrm{WHO}$, an estimated 2.0 million individuals worldwide became newly infected with HIV in 2014. This includes over 220,000 children were below 15 years. Most of these children live in sub-Saharan Africa and were infected by their HIV-positive mothers during pregnancy, childbirth or breastfeeding. ${ }^{3}$ Nearly $5 \%$ of HIV infections are attributable to parent to child transmission in India. Out of estimated 27 million pregnancies every, 49.000 occur to HIV infected women. HIV prevalence rate in pregnant women in cities such as Hyderabad, Mumbai, Pune, Sangli, and Manipur is higher than others that are $2-2.5 \%{ }^{4}$

Nursing personnel should prevent unnecessary intervention that is like early rupture of membrane, routine episiotomy, forceps delivery and vacuum extraction it should only be performed only if there is specific obstetrical indications .Thus, nursing personnel should have enough knowledge and decision making capability to take independent decision during delivery while dealing with HIV positive mother so to prevent mother to child transmission of HIV. ${ }^{5}$

Nurses and Midwives are at front position in spending considerable time taking care of the HIV positive patients who are admitted to hospitals. Midwives are considered to play an essential role whose task is to promote sexual and reproductive health and to prevent reproductive illnesses. Hence, it is important to explore the knowledge of midwives about HIV and their attitudes and willingness to take care of them in order to improve the quality of care. ${ }^{6}$

During pregnancy and delivery, HIV-infected women need access to prevention of mother-to-child transmission services, a skilled birth attendant, and quality post-partum care to prevent HIV infection in the infant and maximize maternal health. Providers may lack resources as well as appropriate training and support to provide such services to

Volume 5 Issue 6, June 2016 www.ijsr.net 


\section{International Journal of Science and Research (IJSR) \\ ISSN (Online): 2319-7064 \\ Index Copernicus Value (2013): 6.14 | Impact Factor (2015): 6.391}

women with HIV. Innovations in biomedical and behavioral interventions may improve reproductive healthcare for HIV infected women. ${ }^{7}$

The present study was undertaken to assess the knowledge and expressed practices regarding PPTCT of HIV among nursing personnel, to determine the relationship between knowledge and expressed practices regarding PPTCT of HIV among nursing personnel and to find out the association of knowledge and expressed practices scores regarding PPTCT of HIV among nursing personnel with selected demographic variables.

\section{Materials and Methods}

This study was conducted in selected health care centers Ambala, District Haryana. Total 100 nursing personnel were selected by convenience sampling. The research approach adopted for the study was non experimental and the design was descriptive correlation survey research design. Paper pencil technique was used to collect data. Informed consent was obtained from nursing personnel and they were assured about confidentiality of their response. Structured knowledge questionnaire and expressed practices checklist tools was used. Statistical analysis was done by using statistical package for social science software program (SPSS) version 20 to calculate frequency, correlation, t- test, ANOVA to test association with selected variables.

Ethical clearance: Ethical clearance was taken from university ethical committee for conducting the study. Formal administrative approval was taken from the Civil Surgeon of Ambala District, Haryana to conduct the final study. The research participants were enrolled in the study after written informed consent and they were assuring about the confidentiality of their response

\section{Results}

A total 100 nursing personnel were selected and their frequency and percentage distribution of selected demographic variables are presented in table 1 .

The data presented in table 1 shows that majority of nursing personnel $(70 \%)$ were in the age group of 21-30 years, $(53 \%)$ were of Hindu religion, $(75 \%)$ were GNM, 98\% had workshop/in-service as source of information, (71\%) had not attended any GFATM classes and less than half $(42 \%)$ had work experience of 1-3 years and (46\%) had cared for HIV in various wards.
Table 1: Frequency and percentage distribution of selected demographic variables, $\mathrm{N}=100$

\begin{tabular}{|c|l|c|}
\hline S. No. & \multicolumn{1}{|c|}{ Selected demographic variables } & $f(\%)$ \\
\hline $\mathbf{1 .}$ & Age (in years) & \\
1.1 & $21-3070$ & 70 \\
1.2 & $31-4023$ & 23 \\
1.3 & $41-507$ & 07 \\
$\mathbf{2 .}$ & Religion & \\
2.1 & Hindu & 53 \\
2.2 & Muslim & 02 \\
2.3 & Sikhs & 45 \\
$\mathbf{3 .}$ & Education & \\
3.1 & ANM & 02 \\
3.2 & GNM & 75 \\
3.3 & B.Sc. Nursing & 12 \\
3.4 & Post basic Nursing & 09 \\
3.5 & M.Sc. Nursing (specify specialty) & 02 \\
$\mathbf{4 .}$ & Work experience in years & \\
4.1 & Less than 1year & 15 \\
4.2 & $1-3$ & 42 \\
4.3 & $4-6$ & 20 \\
4.4 & Above 6 year & 23 \\
$\mathbf{5 .}$ & Source of information regarding Prevention of & \\
& Parent to Child transmission (PPTCT) of HIV. & \\
5.1 & Books/ Journals & 02 \\
5.2 & Workshops/ In service & 98 \\
$\mathbf{6 .}$ & Have you ever cared for a patient with HIV & \\
6.1 & Yes & 46 \\
6.2 & No & 54 \\
$\mathbf{7 .}$ & Had special classes for GFATM & \\
7.1 & Yes & \\
7.2 & No & 71 \\
\hline
\end{tabular}

Figure 1- Shows that majority of nursing personnel (52\%) had below average level knowledge with range of scores 0 15 regarding prevention of parent to child transmission of HIV.

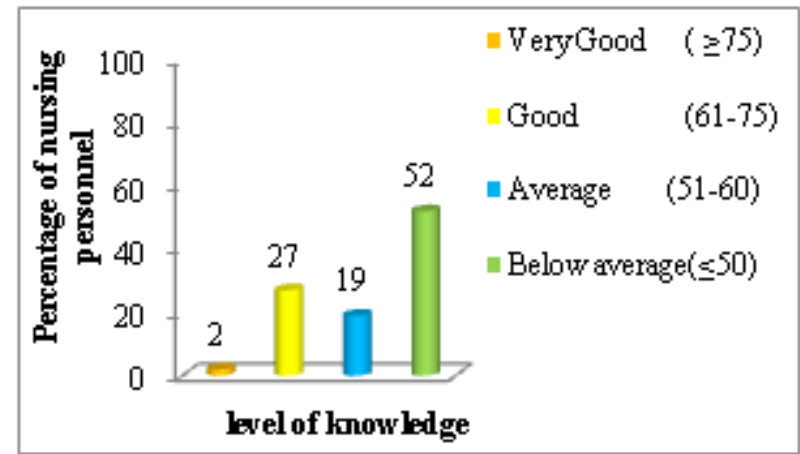

Figure 1: Bar diagram showing the level of knowledge score

Figure 1- Shows that majority $(75 \%)$ of nursing personnel had poor practices regarding prevention of parent to child transmission of HIV. (Fig-2) 


\section{International Journal of Science and Research (IJSR) \\ ISSN (Online): 2319-7064}

Index Copernicus Value (2013): 6.14 | Impact Factor (2015): 6.391

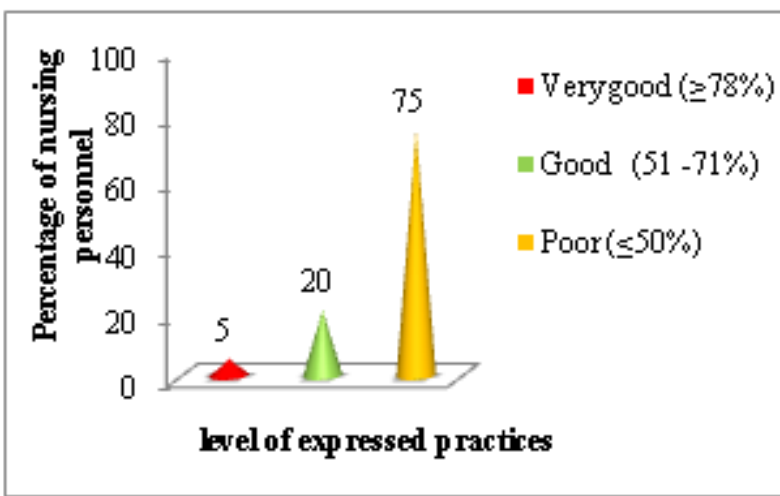

Figure 2: Bar diagram showing the level of expressed practices

The data presented in table 2 shows that the correlation between knowledge and expressed practices scores of nursing personnel was 0.132 which was mild positive and non significant at 0.05 level of significance. There is no significant relationship between the knowledge and expressed practices scores regarding prevention of parent to child transmission of HIV among nursing personnel. (Table 2)

Table 2: Co-relation between knowledge and expressed practices scores regarding prevention of parent to child transmission of HIV among nursing personnel, $\mathbf{N}=\mathbf{1 0 0}$

\begin{tabular}{|l|c|c|}
\hline Nursing personnel score & $\mathbf{r}$ & p-value \\
\hline $\begin{array}{l}\text { Knowledge score } \\
\text { Expressed practices score }\end{array}$ & 0.132 & $0.190^{\text {NS }}$ \\
$\mathbf{r ( 9 9 )}=\mathbf{0 . 1 9 P} \leq \mathbf{0 . 0 5}$ NS-non significant & \\
\hline
\end{tabular}

The association between nurses who had special classes for GFATM was found significant at 0.05 level of significance. There was no significant association of knowledge score with other selected demographic variables

Table 3: ANOVA/t value showing association between knowledge scores regarding prevention of parent to child transmission of HIV among nursing personnel with selected demographic variables, $\mathbf{N}=\mathbf{1 0 0}$

\begin{tabular}{|c|c|c|c|c|}
\hline S. No & Selected demographic variables & F/t value & $\mathrm{df}_{1} / \mathrm{df}_{2}$ & P-value \\
\hline 1. & Age (in years) & \multirow{6}{*}{$2.61_{\mathrm{f}}$} & \multirow{5}{*}{$97 / 2$} & \multirow{5}{*}{$0.07^{\mathrm{NS}}$} \\
\hline 1.1 & $21-30$ & & & \\
\hline 1.2 & $31-40$ & & & \\
\hline 1.3 & $41-50$ & & & \\
\hline 2. & Religion & & & \\
\hline 2.1 & Hindu & & \multirow{3}{*}{$97 / 2$} & \multirow{3}{*}{$0.84^{\mathrm{NS}}$} \\
\hline 2.2 & Muslim & \multirow[t]{2}{*}{$0.17_{\mathrm{f}}$} & & \\
\hline 2.3 & Sikhs & & & \\
\hline 3. & Education & \multirow{6}{*}{$1.93_{\mathrm{f}}$} & \multirow{6}{*}{$95 / 4$} & \multirow{6}{*}{$0.11^{\mathrm{NS}}$} \\
\hline 3.1 & ANM & & & \\
\hline 3.2 & GNM & & & \\
\hline 3.3 & B.Sc. Nursing & & & \\
\hline 3.4 & Post basic Nursing & & & \\
\hline 3.5 & M.Sc. Nursing (specify specialty) & & & \\
\hline 4. & Work experience in years & \multirow{5}{*}{$1.46_{\mathrm{f}}$} & \multirow{5}{*}{$96 / 3$} & \multirow{5}{*}{$0.22^{\mathrm{NS}}$} \\
\hline 4.1 & Less than 1year & & & \\
\hline 4.2 & $1-3$ & & & \\
\hline 4.3 & $4-6$ & & & \\
\hline 4.4 & Above 6 year & & & \\
\hline 5. & Source of information regarding & \multirow{4}{*}{$0.74_{t}$} & \multirow{4}{*}{98} & \multirow{4}{*}{$0.39^{\mathrm{NS}}$} \\
\hline & PPTCT & & & \\
\hline 5.1 & Books/Journals & & & \\
\hline 5.2 & Workshops/ In service & & & \\
\hline 6. & Have you ever cared for a patient & \multirow{4}{*}{$1.18_{\mathrm{t}}$} & \multirow{4}{*}{98} & \multirow{4}{*}{0.27} \\
\hline & with HIV & & & \\
\hline 6.1 & Yes & & & \\
\hline 6.2 & No & & & \\
\hline 7 & Had special classes for GFATM & \multirow{3}{*}{$2.34_{t}$} & \multirow{3}{*}{98} & \multirow[t]{3}{*}{$0.00 *$} \\
\hline 7.1 & Yes & & & \\
\hline 7.2 & No & & & \\
\hline
\end{tabular}

NS-non significant $(\mathbf{p}>\mathbf{0 . 0 5})$

The association of nursing practices with their education qualification (0.04) was found significant at 0.05 level of significance. The association of nursing practices with work experience (0.00) was found significant at 0.05 level of significance. The association between nursing practices who had cared for HIV patient (0.27) was found significant at 0.05 level of significance. The association between nursing 


\section{International Journal of Science and Research (IJSR) \\ ISSN (Online): 2319-7064}

Index Copernicus Value (2013): 6.14 | Impact Factor (2015): 6.391

practices who had classes for GFATM (0.001) was found significant at 0.05 level of significance.

Table 4: ANOVA/t value showing association between expressed practices scores regarding prevention of parent to child transmission of HIV among nursing personnel and selected variables $\mathrm{N}=100$

\begin{tabular}{|c|c|c|c|c|}
\hline S.No & Selected demographic variables & F/t value & $\mathrm{df}_{1} / \mathrm{df}_{2}$ & P-value \\
\hline 1. & Age (in years) & & & \\
\hline 1.1 & $21-30$ & & & \\
\hline 1.2 & $31-40$ & 2.09 .f $_{\mathrm{f}}$ & $97 / 2$ & $0.12^{\mathrm{NS}}$ \\
\hline 1.3 & $41-50$ & & & \\
\hline 2. & Religion & & & \\
\hline 2.1 & Hindu & $0.54_{f}$ & $97 / 2$ & $0.58^{\mathrm{NS}}$ \\
\hline 2.2 & Muslim & & & \\
\hline 2.3 & Sikhs & & & \\
\hline 3. & Education & & & \\
\hline 3.1 & ANM & & & \\
\hline 3.2 & GNM & $2.55_{\mathrm{f}}$ & $95 / 4$ & $0.04^{*}$ \\
\hline 3.3 & B.Sc. Nursing & & & \\
\hline 3.4 & Post basic Nursing & & & \\
\hline 3.5 & M.Sc. Nursing (specify specialty) & & & \\
\hline 4. & Work experience in years & & & \\
\hline 4.1 & Less than 1year & $10.5_{\mathrm{f}}$ & $96 / 3$ & $0.00^{*}$ \\
\hline 4.2 & $1-3$ & & & \\
\hline 4.3 & $4-6$ & & & \\
\hline 4.4 & Above 6 year & & & \\
\hline 5. & Source of information regarding PPTCT & & & \\
\hline 5.1 & Books/Journals & 2.642 & $1 / 98$ & $0.107^{\mathrm{NS}}$ \\
\hline 5.2 & Workshops/ In service & & & \\
\hline 6. & Have you ever cared for a patient with HIV & & & \\
\hline 6.1 & Yes & $2.88_{t}$ & 98 & $0.27^{\mathrm{NS}}$ \\
\hline 6.2 & No & & & \\
\hline 7. & Had special classes for GFATM & & & \\
\hline 7.1 & Yes & 2.34 & 98 & $0.001 *$ \\
\hline 7.2 & No & & & \\
\hline
\end{tabular}

NS-Non significant $(\mathbf{P}>\mathbf{0 . 0 5})$

The association of expressed practices score of nursing personnel regarding prevention of parent to child transmission of HIV with age $(\mathrm{f}=2.09)$, religion $(\mathrm{f}=0.54)$, and those who had cared for a patient with HIV $(\mathrm{t}=2.88)$ were non significant. Whereas $(\mathrm{f}=0.04)$ of nursing personnel regarding education, work experience in years $(\mathrm{f}=0.00)$, and those who had special classes $(t=0.001)$ for GFATM were found statistically significant at 0.05 level of significance.

\section{Discussion}

These finding are also supported by a Chiamaka $\mathbf{N}$ which showed that the greatest source of information on HIV for the majority of professionals was health talks/seminars. Further finding of the present study shows that there is a significant association of knowledge and expressed practices regarding prevention of parent to child transmission of HIV among nursing personnel with those who had special classes of GFATM. The finding is consistent with the finding of the comparative study conducted by Mc Graw and that shows that staff nurses who had attended in-service education programme on PPTCT of HIV had significantly higher knowledge as compared to those who had not attended inservice education programme on PPTCT of HIV. The finding is also consistent with the cross sectional study conducted on knowledge and practices of health care provider towards HIV by Bart Burkhalter where the knowledge was significantly associated with HIV training i.e. $82 \%$ versus $25 \%, \mathrm{p}=0.00$.
The following conclusion was drawn on the basis of finding of the study. Nursing personnel had below average knowledge and had poor practices regarding prevention of parent to child transmission of HIV. There was no significant co- relation between knowledge and expressed practices scores of nursing personnel while there was significant association of knowledge and expressed relationship between nurses who had special classes for GFATM and also those who had more work experience.

\section{Acknowledgements}

The researcher would like to thank nursing personnel for their corporation

\section{References}

[1] Parent to child transmission of HIV. Available at https://aidsinfo.nih.gov/education-materials/factsheets/20/50.

[2] MTCT transmission. Available at http://www.unaids (2010).

[3] Worldwide newly infected children in 2014. C http://www.who.com (2014).

[4] Ram Manohar Mishra, Madhulika Dube. Changing epidemiology of HIV in Mumbai.2012.

[5] HIV transmission from parent to child transmission of HIV. Available from http; //www.unaids guide line 2012. 


\section{International Journal of Science and Research (IJSR) \\ ISSN (Online): 2319-7064}

Index Copernicus Value (2013): 6.14 | Impact Factor (2015): 6.391

[6] NACO guideline 2012. Available from http;//www.naco.guideline 2012.

[7] Joyce N Mumah, Adhalah K. Ziraba. Effect of HIV status on fertility intention and contraceptive use among women in nine sub-Saharan African countries: evidence from Demographic and Health Surveys.2014; 7(10). Available at www.ncbi.nlm.nih.gov.

[8] Bart burkhalter. Evaluation of knowledge, attitudes, and practices of health care providers toward HIV-positive patients in Tanzania.2012.available from www.qaproject.org.

[9] Chiamaka N. Knowledge, Beliefs and Attitudes about HIV/AIDS related issues, and the Sources of Knowledge among Health Care Professionals in Southern Nigeria. J R Soc Promot Health. 2010 September; 128(5): 233-239. 